\title{
EDITORIAL
}

\section{Ethics, Support for Care, Prevention, and What's Important}

\author{
Kurt C. Stange, $M D, P b D$, Editor \\ Ann Fam Med 2010;8:290-291. doi:10.1370/afm.1149
}

$\mathrm{T}$ his issue of the Annals addresses ethical issues, ${ }^{1,2}$ the effects of implementing new models of care support, ${ }^{3,4}$ prevention, ${ }^{5}$ screening, ${ }^{6-8}$ and patients' health information-seeking behaviors. ${ }^{9}$ It closes with a new approach for calculating the complexity of patient visits ${ }^{10,11}$ and a community celebration of the life of a personal physician. ${ }^{12}$

An essay by bioethicist and family physician Howard Brody ${ }^{1}$ argues the ethical issues surrounding the American Academy of Family Physicians (AAFP) receipt of a corporate donation from Coca-Cola to fund patient education. AAFP President Lori Heim presents a counterargument. We look forward to a thoughtful dialogue of this issue in the Annals' online discussion and at state chapter meetings of the Academy around the country this summer preceding the AAFP's fall Congress of Delegates.

The Annals Journal Club selection ${ }^{13}$ examines the effects of implementing a new model of support for care of chronically ill older adults. In a cluster-randomized trial, ${ }^{3}$ this Guided Care model shows promising outcomes from the physician's point of view.

A qualitative study by Shield et al examines a different change in care processes-implementation of an electronic medical record in a residency-training practice. ${ }^{4}$ The authors find both expected and unanticipated effects on the process of care and on relationships with patients and among practice members.

A cluster of articles addresses disease prevention and early detection.

Abramson and colleagues help us to proactively plan for the next influenza season with a clinical trial evaluation of a multifaceted but feasible intervention to increase staff influenza vaccination rates. ${ }^{5}$

Another study takes a longitudinal perspective on the use of colorectal cancer screening. Doubeni and colleagues identify a constellation of factors associated with colorectal cancer screening in Medicare beneficiaries. ${ }^{6}$

The population prevalence of cardiovascular risk factors and cholesterol screening in young adults is examined by Kuklina et al, with the surprising finding of no difference in screening rates for those with and without risk factors. ${ }^{7}$

The largest exclusively primary care validation study of the Patient Health Questionnaire (PHQ) 2and 9 -item measures provides helpful and actionable information on the use of these measures to screen for depression in primary care. ${ }^{8}$

A qualitative study by Longo and colleagues examines how people with diabetes seek and use health information, identifying the interaction of both active and passive information receipt. ${ }^{9}$

In an article with important policy implications, Katerndahl and colleagues ${ }^{10}$ elucidate a new approach for calculating the complexity of patient visits. An editorial by Lee Green puts this work into context and draws out the implications. ${ }^{11}$

Finally, a moving essay by Larry Green and Bill Phillips $^{12}$ helps us to focus on what is important about family medicine by witnessing the effect of a family doctor's life through the eyes of his community.

Please join the online discussion of these articles at http://www.AnnFamMed.org.

To read or post commentaries in response to this article, see it online at http://www.annfammed.org/cgi/content/full/8/4/290.

\section{References}

1. Brody H. Professional medical organizations and commercial conflicts of interest: ethical issues. Ann Fam Med. 2010;8(4):354-358.

2. Heim L. Identifying and addressing potential conflict of interest: a professional medical organization's code of ethics. Ann Fam Med. 2010;8(4):359-361.

3. Marsteller JA, Hsu YJ, Reider L, et al. Physician satisfaction with chronic care processes: a cluster-randomized trial of Guided Care. Ann Fam Med. 2010;8(4):308-315.

4. Shield RR, Goldman RE, Anthony DA, Wang N, Doyle RJ, Borkan J. Gradual electronic health record implementation: new insights on physician and patient adaptation. Ann Fam Med. 2010;8(4):316-326.

7. Abramson ZH, Avni O, Levi O, Miskin IN. Randomized trial of a program to increase staff influenza vaccination in primary care clinics. Ann Fam Med. 2010;8(4):293-298. 
6. Doubeni CA, Laiyemo AO, Young AC, et al. Primary care, economic barriers to health care, and use of colorectal cancer screening tests among Medicare enrollees over time. Ann Fam Med. 2010;8(4):299-307.

7. Kuklina EV, Yoon PW, Keenan NL. Prevalence of coronary heart disease risk factors and screening for high cholesterol levels among young adults, United States, 1999-2006. Ann Fam Med. 2010;8(4):327-333.

8. Arroll B, Goodyear-Smith F, Crengle S, et al. Validation of PHQ-2 and $\mathrm{PHQ}-9$ to screen for major depression in the primary care population. Ann Fam Med. 2010;8(4):348-353.
9. Longo DR, Schubert SL, Wright BA, LeMaster J, Williams CD, Clore $J N$. Health information seeking, receipt, and use in diabetes selfmanagement. Ann Fam Med. 2010;8(4):334-340.

10. Katerndahl DA, Wood $R$, Jaén $C R$. A method for estimating relative complexity of ambulatory care. Ann Fam Med. 2010;8(4):341-347.

11. Green LA. The implications of measuring complexity. Ann Fam Med. 2010;8(4):291-292.

12. Phillips WR, Green LA. A public celebration of a personal doctor. Ann Fam Med. 2010;8(4):362-365.

13. Guided Care. Annals Journal Club. Ann Fam Med. 2010;8(4):iii.

\title{
EDITORIAL
}

\section{The Implications of Measuring Complexity}

\author{
Lee A. Green, MD, MPH \\ Department of Family Medicine, University of Michigan Medical School, Ann Arbor, Michigan
}

Ann Fam Med 2010;8:291-292. doi:10.1370/afm.1147.

I $\mathrm{n}$ this issue of the Annals, Katerndahl, Wood, and Jaén wade boldly into deep waters indeed: attempting to quantitatively evaluate the complexity of outpatient medical care. This work was first presented 7 years ago, and the lengthy delay in publication illustrates the conceptual and methodological difficulty of this subject. The article will be beaten up, as such pioneering work typically is, but it is not important whether this particular measure of relative complexity is right—it is important that the authors have offered a rigorous quantitative measure to debate. As Box has pointed out, "All models are wrong, but some are useful."

Is this model of complexity of outpatient care useful? Since their approach is explicitly based on the assumption that they are measuring a complex nonlinear system, there are 2 issues that must be distinguished in evaluating it. One is the measurement of complexity; the other, and more important, is whether what is being measured is in fact a complex nonlinear system. The authors provide a sound grounding in information theory for their measurement, and they find also that the same rank-ordering of findings

Conflict of interest: none reported

\section{CORRESPONDING AUTHOR}

Lee A. Green, MD, MPH

1018 Fuller, Campus SPC 1213

Ann Arbor, MI 48109

greenla@umich.edu emerges when other approaches are applied to their sample. Hence, the measurement itself is reasonable.

It is one thing to calculate a statistic, however, and quite another to ask whether it means anything. Is the system being measured in fact a complex nonlinear system, one whose underlying dynamics are described by complexity science? And if so, what does that imply for measurement?

Leading thinkers in family medicine have long believed that complex systems theory can help us understand the dynamics of primary care and of primary care practices. ${ }^{2}$ The footprints of complexity seem to be present: systems with rich patterns of behavior, sometimes surprising behavior, self-similarity across scales, interconnectedness, and positivefeedback interactions among agents. But while we see complexity's footprints, we have yet to capture the beast-to prove that the mathematics of complex nonlinear dynamics describe primary care and those of traditional linear modeling approaches do not.

Not all that is complicated is complex. A system with many inputs and outputs and many functions, each of which behaves in an essentially linear fashion, can produce rich and sometimes surprising patterns of behavior and contain a great deal of information. Such a complicated system is best described by a large number of linear equations, and its behavior is theoretically fully predictable even if hard to predict in practice. A complex nonlinear system, on the other hand, is very simple in the sense that a very small number of equa- 